\title{
O processo de criação artística de ilustradores de livros de imagem e a constituição de leitores
}

\author{
Hanna Talita Gonçalves Pereira de Araújo
}

Resumo: Este artigo visa a uma aproximação com o processo criativo de artistas ilustradores de livros de imagem no sentido de compreender os modos de sua produção poética e criativa da narração visual. A partir deste enfoque na produção das obras, buscamos atentar para o potencial narrativo das imagens, e para seu papel na constituição de leitores. Para o desenvolvimento deste estudo, escolhemos três renomados artistas na categoria livro de imagem, cujos processos criativos de construção narrativa serão o objeto do estudo. A abordagem da psicologia que fundamenta a pesquisa é a sociocultural, com apoio das contribuições de Fayga Ostrower no campo das artes visuais. Os dados foram coletados por meio de entrevistas semiestruturadas, filmadas em vídeo e transcritas. Também foram estudadas as sequências narrativas das ilustrações com o intuito de apreender diferenças e especificidades da narração nas modalidades escrita e pictórica.

Palavras-chave: L

Abstract: This article looks at approaching the creative process of illustrator artists to understand theirs poetic and creative production in a visual narrative. From the focus on the work production, we seek to consider the narrative potential of images, and their role in the constitution of readers. To develop this study 
we chose three renowned artists in the category of picture book and we will study the creative process of narrative construction of them. The approach of psychology whichbears this search is the sociocultural, through the contribution of Fayga Ostrower in the field of visual arts. The data were collected through semistructured interviews, filmed on video and transcribed. The sequences of narrative illustrations also were studied in order to capture differences and particularities in terms of written and pictorial narration .

Keywords: Picture-book, Childhood, Visual narratives.

\section{Introdução}

Este artigo visa a uma aproximação com o processo criativo de artistas plásticos através de seus dizeres sobre a obra já finalizada e como esse pode oferecer subsídios que, aliado à mediação de leitura, podem ampliar o aproveitamento das atividades de leitura de literatura infantil. Este trabalho é um desdobramento da pesquisa de mestrado em artes visuais desenvolvida junto ao Instituto de Artes da Universidade Estadual de Campinas, financiado pela FAPESP - Fundação de Amparo à Pesquisa do Estado de São Paulo.

O processo de criação de ilustrações para livros infantis tornou-se tema instigante no final da graduação em pedagogia. Observamos que a presença de ilustrações em livros infantis tem papel preponderante na significação com a literatura. Um livro se torna mais convidativo se possui ilustraçôes, e se tratamos de crianças pequeninas, não alfabetizadas, são as ilustrações que terão o dever de trazê-las para a leitura.

A relação entre a criança e o livro como suporte é estabelecida desde o contato inicial: as crianças menores colocam os livros na boca, como se estivessem os experimentando ao seu modo, 
ou estabelecem um jogo lúdico no ir e vir das páginas; quando maiores elas desenham sobre as ilustrações, como se buscassem complementar o desenho. Encenam suas histórias ou inventam outras a partir dos desenhos. Elas vivem a literatura infantil. Se pensarmos nas produções voltadas primordialmente à criança, a imagem presente em um livro se mostra para a criança pequena como um interlocutor lúdico, que nomeia e é nomeado, que esconde e se desvela, que constrói significados com a literatura infantil e seus mediadores, sejam pais, professores ou demais crianças. E, acima de tudo, permite inúmeras possibilidades de leitura!

Para desenvolver este estudo em ilustração de livros infantis, focamos produções nas quais a imagem tem papel privilegiado e são detentoras do eixo narrativo. Os livros de imagem são produções em que a narrativa acontece através da composição imagética, não atendo-se à palavra escrita. Desse modo, é um material acessível a muitos e diferentes olhares, que agrega leituras desde as crianças pequenas até os adultos.

Ao buscar compreensão das intenções poéticas dos artistas quando produzem suas imagens direcionadas para a infância, adquirimos mais ferramentas para a leitura de imagens e, do mesmo modo, ampliamos nossa compreensão na leitura de imagem, aperfeiçoando-nos como mediadores.

\section{Referencial teórico: linguagem e imagem}

A abordagem da psicologia que fundamenta a pesquisa éa sociocultural (tendo Lev S. Vygotsky como principal expoente), com apoio das contribuiçóes de Fayga Ostrower no campo das artes visuais.

Tomamos como suporte teórico na linguagem visual o trabalho e a concepção de criação de Fayga Ostrower (1990). Ostrower produziu diversas publicações em que aborda a questão da criatividade e os processos de criação (1987; 1990; 1997), as quais se relacionam diretamente com o objeto deste trabalho. Para Ostrower (1990, p. 17), 
[...] na arte, as formas expressivas são sempre formas de estilo, formas de linguagem, formas de condensação de experiências, formas poéticas. Nelas se fundem a uma só vez o particular e o geral, a visão individual do artista e da cultura em que vive, expressando assim certas vivências pessoais que se tornaram possíveis em determinado contexto cultural.

Desse modo, podemos interpretar que, ao produzir criativamente, o ilustrador posiciona-se e ao produzir algo destinado ao universo infantil, suas vivências e concepções de infância são proeminentes e se fazem presentes em sua obra artística. Da mesma forma, as vivências que compartilha com a sociedade na qual está inserido estarão presentes em seu trabalho.

Partimos da concepção de mediação semiótica elaborada por Vygotsky (2000), na qual os sujeitos sociais se relacionam através de signos, sejam eles visuais, verbais, sonoros etc. Este sujeito cognitivo de que nos fala Vygotsky é eminentemente semiótico e cultural, constituído nas relações com os outros (SMOLKA, 1997). Ademais, entendemos que a produção artística é destinada a um público específico, com intençôes delineadas a um receptor idealizado. Para tanto, apoiamo-nos no princípio dialógico defendido por Bakhtin (1992), em que a enunciação pressupõe o outro, sendo que este diálogo demanda signos, e os signos são sempre signo-a-interpretar. Deste modo, o artista criador do livro de imagem o produz para o leitor e seu livro somente comunica no momento em que ele é aberto e sobre ele alguém lhe põe os olhos. É neste momento que ele está pronto. É nesta interação que o livro de imagem acontece, através deste diálogo do artista e da criança, tendo o livro com suporte material detentor dos signos que foram grafados pelo artista.

No entanto, ao criar, o artista não precisa, necessariamente, estar consciente das influências que o auxiliam no processo criativo. De acordo com Ostrower (1990, p. 17),

[...] ao criar, o artista não precisa teorizar a respeito de suas vivências, traduzir os pensamentos e as emoçóes em palavras. 
Ele tem mesmo que viver a experiência, incorporá-la em seu ser sensível, conhecê-la por dentro. Daí, espontaneamente, lhe virá a capacidade de chegar a uma síntese dos sentimentos - naquilo que a experiência contém de mais pessoal e universal - e de transpor esta síntese para uma síntese de linguagem, adequando as formas ao conteúdo.

Compreendemos que o artista, quando da produção de suas obras, deixa marcas de diversas naturezas na obra sem que esteja necessariamente consciente desses gestos. Buscamos nas falas dos artistas entrevistados quais são os elementos de construção de sentido que foram calcados intencionalmente por eles nas imagens, com a clara distinção que o fazer pode ocasionar/direcionar a leitura da imagem, conduzindo o olhar do leitor. No entanto, procuramos, também, nas falas dos artistas, sinais que lhes foram percebidos após o contato com leituras alheias, e que ressignificaram suas próprias percepçóes da imagem que eles mesmos produziram.

E neste ponto nós deteremos na constituição da obra de arte, que acontece, e se faz obra de arte, quando se encerra o ciclo do qual Bakhtin nos fala. A obra se torna arte se essa estiver relacionada dialeticamente entre conteúdo, forma e material. A arte, como qualquer produção humana, está na e para a sociedade, sendo feita por e para sujeitos sociais. Deste modo, a sociedade afeta a arte ao mesmo tempo em que busca resposta direta e intrinsecamente dentro dela (BAKHTIN, 1992).

Por esse viés, o significado da obra não é estático, já que, a cada leitura da obra, os observadores são outros. Podemos pensar nesta flexibilidade na leitura de uma obra sem que contemos obrigatoriamente com observadores diferentes. A leitura feita na infância toma outro sentido de acordo com as novas leituras realizadas ao longo da vida. Quantos pormenores passaram despercebidos e quantos outros detalhes são descobertos quando vistos com maior apreensão. As imagens daquele livro de infância guardado durante anos na estante mudaram numa releitura anos adiante? Não e sim. Não, pois as mesmas marcas que foram calcadas pelo artista permanecem, não recebendo 
nenhum retoque. Sim, se pensamos o livro como obra somente finalizada quando se encerra o ciclo, incluído como peça-chave neste processo o olhar do leitor. A história só existe se ela for lida, e se neste caso hipotético que criamos, se ela for relida anos mais tarde, depois de anos de vivências e ampliação do repertório de vida do sujeito, a leitura não será a mesma, as ilustrações não serão as mesmas, do mesmo modo que a pessoa já não é a mesma. Alberto Manguel fala sobre a instabilidade nas leituras realizadas da mesma imagem, segundo ele (2000, p. 25),

Com o correr do tempo, podemos ver mais ou menos coisas em uma imagem, sondar mais fundo e descobrir mais detalhes, associar e combinar com outras imagens, emprestar-lhe palavras para contar o que vemos mas, em si mesma, uma imagem existe no espaço que ocupa, independentemente do tempo que reservamos para contemplá-la.

Deste modo, a flexibilização da obra artística permite que sejam redescobertos significados, agregando novos sentidos à obra. De acordo com as experiências anteriores, o contato com novos livros, pessoas, a possibilidade de (re)leitura se expande tanto no plano horizontal, no encontro de novas obras, como no plano vertical, quando da ampliação de repertório, ganhase ferramentas para o aprofundamento em leitura já realizada anteriormente. Manguel refere-se a essa capacidade de releitura do leitor ao aprofundamento de níveis de leitura, no qual, a cada leitura, existe uma possibilidade de atingir uma camada mais interior na leitura da obra de arte.

\section{O Processo Criativo e a formação de leitores}

A responsabilidade social do artista que produz para a infância está além de entreter, está para envolver e seduzir um peculiar interlocutor que inicia sua trajetória de leitura e assim o faz através de seu processo criativo. A ilustração de um livro não 
é um mero colocar de representações na folha que correspondem a sentidos de frases escritas; quando o artista trabalha no livro, ele busca atribuir sentidos na imagem que constrói, sendo estas detentoras de uma poética e de uma estética própria, derivadas do processo criativo do artista e fixadas na imagem. O processo de construção de uma narrativa por imagens exige do artista, além da técnica, consciência das estruturas necessárias para alicerçar a narrativa. Angela-Lago, autora e ilustradora de livros para crianças, reflete sobre essa complexidade do momento de estruturação de um livro de imagem quando diz que (1991, p. 62)

Arquitetar um livro é arquitetar uma cidade. Num livro de imagens é preciso virar a página como quem está conhecendo uma cidade e vira uma esquina para desvendar um novo campo visual. É por isso que antes de se projetar cada desenho, se projeta o volume. Não se trata de pintar uma série de quadros. Há toda uma conjunção necessária, todo um ritmo, um movimento, uma tensão, uma direção que perpassa o trabalho como um todo.

O artístico acontece como uma forma especial de interrelação entre criador e contemplador, calcada em uma obra de arte. É através da poética estabelecida pelo artista e fixada na imagem, em conjunção com a leitura realizada pelo observador, que a obra de arte cumpre sua função social, sua razão de ser: comunicar, expressar, dentre outros.

Nessa capacidade de fruição do objeto artístico focamos nossa preferência no livro de imagem, que se apresenta como uma obra de arte que, por ter por suporte um livro, lhe é conferida maior capacidade de disseminação e, portanto, de contemplações.

Ademais, a imagem contém inúmeras possibilidades narrativas não podendo o ser humano, como ser criativo, observar uma imagem sem que dela absorva essa sua potencialidade narrativa. Estando essa leitura imbricada no cotidiano do meio social no qual o sujeito-contemplador está inserido.

Do mesmo modo, a leitura de imagem ultrapassa a mera identificação dos elementos presentes dentro da ilustração. O jogo 
existente entre os diversos elementos que compõem a ilustração é responsável pela construção e sustentação da narratividade da imagem e, por isso, a criação de tais ilustrações pede um alto grau de habilidade técnica e sensibilidade por parte dos artistas, do mesmo modo que exige um olhar mais atento do observador.

O processo de criação artística do ilustrador de literatura infantil reverbera de tal modo na leitura das crianças que entendemos ser esta responsabilidade muito maior do que um simples colocar de desenhos aleatórios na página em branco. $\mathrm{O}$ artista ao se colocar nas imagens e servir visualmente a criança está favorecendo a ampliação do repertório imagético e, consequentemente, de palavras para os pequenos.

A imagem pede palavra. A cada imagem temos um enunciado. Ainda que numa composição de imagens fiquemos atônicos, mudos, é como se essa imagem, essa ilustração, evocasse tantas palavras que elas se entalam em nossa garganta e não permita que nenhuma escape, e daí vem o sentimento de maravilhamento, que é a própria fruição artística. Do mesmo modo, um texto bem escrito pode evocar tantas imagens que nos atordoam.

Deste modo, acreditamos que a imagem não deve ser oferecida apenas às crianças que não dominam a palavra escrita. Pelo contrário, o hábito da leitura de imagem, isoladas ou em sequência narrativa, como o livro de imagem, por exemplo, assim como o hábito de leitura de textos escritos, ampliam significativamente nossa capacidade de escrita e imaginação. Este exercício do olhar estimula a qualidade da leitura, que se expande a cada passar de olhos pela obra, fazendo com que a qualidade da capacidade de leitura se expanda de forma exponencial. O grau de complexidade de uma imagem deve, assim como no texto escrito, ser alterado circunstancialmente podendo, desse modo, instigar o leitor a buscar novos caminhos e possibilidades de leitura.

Partindo dessa necessidade de leitura da imagem como constante na vida de leitor, pensamos como a falta de hábito ou até mesmo o analfabetismo na leitura de imagem pode comprometer a fruição nas artes, principalmente em artes visuais. Ao se deparar 
com uma obra de arte, o olhar mais displicente emite juízo de valor quando adjetiva: feio, bonito, esquisito, interessante etc. No entanto, o olhar mais educado, mais apurado, percorre os caminhos sugeridos pelo artista, busca a narratividade presente nas obras (no caso de obras figurativas), se embala nos dizeres do artista etc.

Proporcionar atividades de leitura individual ou mediada implica um conhecimento prévio da obra apresentada, sem, no entanto, contar com receitas de olhar. As crianças têm capacidade imaginativa infinitamente superior à dos adultos. As crianças não se prendem e não partem de ideias preconcebidas, como já está marcado nosso olhar adulto. O cinema, a televisão e o texto escrito nos ensinam um modo de olhar que nos condiciona a ver tudo por esse modo, por esta janela.

A leitura de uma imagem por uma criança pode ser totalmente contrária à expectativa do artista, quando da concepção do projeto. Ainda que haja na imagem uma objetividade incutida, por exemplo, numa composição em que consta uma menina e um cachorro, nunca imaginaremos que seja um carro e um foguete, a objetividade presente na imagem nos conduz para narrativas que traspassarão este eixo menina-cachorro, podendo expandir por muitos pontos, por exemplo, era uma vez uma menina e um cachorro que, na verdade, eram extraterrestres disfarçados...

Do mesmo modo, a mesma imagem pode dialogar com diversas idades, de acordo com as experiências de vida serão as leituras possíveis de uma mesma imagem. Por exemplo, um recurso muito utilizado na composição da imagem para marcar a sequência de ações no espaço é a repetição do mesmo personagem em diversos pontos da mesma imagem, recurso narrativo extraído do quadrinho (HQ). No entanto, a criança pequenina dificilmente verá que é o mesmo personagem, ainda que esse contenha as mesmas características. Esta abstração narrativa é compreendida com certa idade e pede um amadurecimento visual que é favorecido também no contato com outras linguagens.

A sequência narrativa é outro ponto que é desenvolvido de acordo com o desenvolvimento da capacidade leitora da criança. 
Bebês dificilmente folheiam os livros ou se prendem ao conteúdo narrativo. Eles se extasiam em uma ou outra ilustração. E, neste momento, outros pontos podem ser utilizados para o contar histórias, como a entonação da voz, a nomeação dos personagens, o som característico de cada um etc.

Buscamos, no desenvolvimento deste estudo, auxiliar as atividades de mediação de leituras de imagem, oferecendo subsídios para estes mediadores. Acreditamos que o trabalho artístico tem uma intencionalidade educativa, ainda que de forma inconsciente. Ao criar, o artista busca mostrar uma forma carregada de conteúdo, e estes dois partem de uma percepção de infância. Ao dialogar com esse artista, que produz para crianças, buscamos compreender quais são suas intencionalidades poéticas, estéticas e, sobretudo, educativas.

\section{Metodologia}

Ao olharmos para o processo de criação de um artista que produz ilustrações para livros de imagem, pensamos que sua produção é um objeto artístico, ainda que se apresente de forma não tradicional, através de imagens impressas, algumas vezes denominado de artes gráficas. As imagens mantêm a concretude artística mesmo que se apresentem ao contemplador tendo como suporte material um livro.

Este estudo tem as características de uma pesquisa qualitativa (LÜDKE; ANDRÉ, 1987), uma vez que o ambiente natural do artista é a nossa fonte direta de dados. Sendo os dados coletados predominantemente descritivos.

Preferimos focar a coleta de materiais na entrevista com os artistas, pois nos pautaremos nos dizeres do artista sobre a obra finalizada e sobre os esboços e materiais do processo de criação, sendo que o significado que as pessoas dão às coisas e à sua vida foco de atenção especial dos pesquisadores, na tentativa de capturar a perspectiva dos participantes (LÜDKE; ANDRÉ, 1987). 
Para o estudo a que nos propusemos, tínhamos de escolher alguns artistas. Iniciamos a busca através de um levantamento das produções brasileiras e detectamos que a partir da década de 90 houve um aumento significativo nas produções do gênero, dado o incentivo advindo de projetos de leitura fomentados pelos governos. Selecionamos os artistas que produzem este tipo de material e que possuíam alguns títulos. A etapa seguinte consistiu na contemplação dos títulos que havíamos escolhido. Neste ponto, utilizamos como critério de escolha a fruição e o deleite do objeto artístico. Este momento representou grande dificuldade dado o número de artistas que produziam livros de imagem de qualidade, que nos agradavam e que, a nosso ver, contemplavam as características que julgamos essenciais em um livro de imagem, em questões estéticas, poéticas e pedagógicas. Para focarmos em três artistas, número que acreditamos como uma amostra suficiente da produção brasileira, estipulamos critérios objetivos. Estabelecemos um índice que atesta a qualidade de produção artística, qual seja, o reconhecimento dos pares por meio da premiação. Assim, selecionamos três artistas que tenham recebido algum dos prêmios de Melhor Ilustração e/ ou Melhor Livro de Imagem pela FNLIJ (Fundação Nacional do Livro Infanto-juvenil) e/ou Prêmio Jabuti, da Câmara Brasileira do Livro, na categoria Ilustração Infantil. Outro critério de escolha dos artistas estava na produção de uma diversidade de livros de imagem, para que esses tenham certa variedade de repertório técnico das ilustrações.

Os artistas escolhidos foram:

1. André Neves: artista plástico, pernambucano, autor de muitos títulos, alguns deles premiados. É autor dos livros de imagem sem texto: Seca (Paulinas, 2000), Mestre Vitalino (Paulinas, 2000), Casulos (Global, 2007) e Brinquedos (Mundo Mirim, 2009).

2. Angela-Lago: artista plástica, mineira, fez curso técnico em desenho gráfico na Escócia. Tem mais de trinta obras publicadas no Brasil e no exterior e traz no currículo incontáveis prêmios e indicações nos mais diversos países. 
É autora dos livros de imagem sem texto: Outra Vez (Editora Miguilim, 1984), O Cântico dos cânticos (Paulinas, 1992) e Cena de Rua (RHJ, 1994).

3. Graça Lima: Ilustradora e designer, carioca, doutoranda em Comunicação Visual pela Escola de Belas Artes da UFRJ, Mestre em Design pela PUC-RJ. Ilustrou muitos livros e recebeu premiações por alguns títulos. Autora dos livros de imagem sem texto: Sai da lama Jacaré (Paulinas, 2000), Só tenho olbos pra você (Paulinas, 1998), Hora da Bóia (Paulinas, 1994) e Noite de cão (Salamandra, 1991).

O material empírico utilizado nesta pesquisa consiste em entrevistas semiestruturadas realizadas com os ilustradores, bem como com um pesquisador na temática de ilustração de livro infantil.

Buscamos estudar, através das entrevistas com os artistas, $\mathrm{O}$ processo de produção e de constituição da poética nas suas obras, buscando o significativo emergente do(s) processo(s) de criação.

Além de entrevistar os artistas, realizamos a análise de três livros por artista/autor ( uma variedade na linguagem plástica, de público pretendido (quanto à faixa etária), quanto à polissemia, ao detalhamento, ao enquadramento, além das opçôes (técnicas, poéticas), histórias paralelas nas margens - que mostram como a narrativa se dá.

Além de entrevistar os artistas, optamos por realizar entrevista com um pesquisador especialista na área de literatura infantil, na qual buscamos aproximar a fundamentação teórica com o material empírico. Escolhemos Luís Hellmeister de Camargo, Autor da Dissertação de Mestrado: Poesia infantil e ilustração: estudo sobre "ou isto ou aquilo" de Cecilia Meireles, (1998); e da tese de Doutorado: Encurtando o Caminho Entre Texto e Ilustração: Homenagem a Angela-Lago, 2006. Ambas junto ao Instituto de Estudos da Linguagem - UNICAMP. Entrevistar Luís Camargo nos pareceu essencial, dado seu conhecimento aprofundado na área, sendo um dos únicos a discutir livros de imagem no país, 
e também por possuir a peculiaridade de ser um artista plástico por formação, além de possuir alguns títulos de literatura infantil, como autor e ilustrador. A entrevista já foi realizada e está em processo de transcrição.

As entrevistas vídeo-gravadas serão editadas e servirão como material complementar na análise do material empírico. As imagens são essenciais para compreensão da entrevista, já que a fala dos artistas está pautada em imagens, sendo a partir do apontar da imagem que o artista nos conduz em seu processo criativo.

\section{Considerações finais}

Este estudo encontra-se em andamento, e tem por intento auxiliar no aproveitamento do livro de imagem como ferramenta para a construção de práticas de leituras. $\mathrm{O}$ foco no processo de criação das imagens é entendido como um elemento esclarecedor na constituição da imagem e sua composição poética e estética. Este estudo tem por interesse ampliar o entendimento do livro de imagem como objeto potencializador da capacidade de leitura de imagem e da construção da narratividade imagética por parte da criança. Por outro lado, apostamos no livro de imagem, também, como elemento capaz de instigar a prática da escrita em crianças em fase de alfabetização.

O livro de imagem permite que a criança imagine a história a partir de suas próprias percepções, sendo guiada através das marcas calcadas pelo artista durante seu processo de criação. Ao virar as páginas, as crianças compreendem paulatinamente a composição da imagem e de como ocorrem as manifestaçốes narrativas no livro de imagem. Este letramento visual é responsável pelo desencadeamento de outras habilidades, tais como a construção da sequência narrativa, ampliação da capacidade de observação de imagens, bem como o estímulo à escrita. 


\section{Referências}

BAKHTIN, Mikhail. Marxismo e Filosofia da linguagem. Traduzido por Michel Lahud. São Paulo: Hucitec, 1992.

LAGO, Angela. A ilustração dos textos para crianças e jovens e a computação gráfica. In: RIBEIRO, Francisco Aurelio (org.). Leitura e literatura infanto-juvenil: ensaios. Vitória: UFES, p. 62-64, 1997.

LÜDKE, Menga; ANDRÉ, Marli. Pesquisas em Educação: abordagens qualitativas. São Paulo: EPU, 1986.

MANGUEL, Alberto. Lendo imagens: uma história de amor e ódio. São Paulo: Companhia das Letras, 2001.

OSTROWER, Fayga. Acasos e Criação Artística. Rio de Janeiro: Campus, 1990.

. Criatividade e Processos de Criação. Petropólis: Vozes, 1997.

REILY, Lucia. As imagens: o lúdico e o absurdo no ensino de arte para pré-escolares surdos. In: Silva, I; Kauchakje, S; Zilda, G. (orgs). Cidadania, surdez e lingnagem: desafios e realidades. São Paulo: Plexus Editora, 2003.

. Armazém de imagens. Campinas: Papirus, 2001.

SMOLKA, Ana Luiza B. A criança na fase inicial da escrita: a alfabetização como processo discursivo. São Paulo: Cortez; Campinas: Ed. Unicamp, 1988.

. A significação nos espaços educacionais: interação social e significação. São Paulo: Papirus, 1997.

TESSLER, Elida. O Meio Como Ponto Zero: Metodologia de Pesquisa em Artes Plásticas. Porto Alegre: UFRGS, 2002.

VYGOTSKY, Lev. La imaginación y el arte en la infancia. Delegación Coyoacán: Fontamara, 1997.

. Linguagem, Desenvolvimento e Aprendizagem. Traduzido por Maria da Penha Villalobos. São Paulo: Icone, EDUSP, 1988.

- A Formação Social da Mente: o desenvolvimento dos processos psicológicos superiores. São Paulo: Martins Fontes, 2000. 